\title{
High-Frequency Chest Wall Compressions: Good for the Patient? Good for the Clinician?
}

Chest physiotherapy practice may vary across intensive care units, hospitals, and countries, including the techniques used and the professionals that deliver the intervention. ${ }^{1}$ There are also variations in methods of patient referral (if required), treatment goals, and selection of interventions. ${ }^{1-3}$ Chest physiotherapy goals may include the enhanced clearance of airway secretions, the optimization of gas exchange, and/or the re-expansion of collapsed lung. ${ }^{4}$

Recent recommendations for the management of retained airway secretions in the non-intubated critically-ill patient include interventions to increase lung volume and/or increase expiratory flow. ${ }^{1}$ Other methods may include manual-assisted cough, oral and/or nasopharyngeal suctioning, or assistive devices such as mechanical in-exsufflation. ${ }^{1}$ For the intubated and ventilated patient the use of body positioning or mobilization, manual and/or ventilator hyperinflation, and airway suctioning are recommended. ${ }^{1} \mathrm{Ev}$ idence supporting these recommendations has been based on limited randomized controlled trials, observational trials, non-randomized trials, or expert opinion. ${ }^{1,4}$ Manual techniques such as chest wall percussion and chest wall vibrations/compressions (when combined with positioning and breathing exercises, often termed conventional chest physiotherapy/physical therapy or CCPT) may also have a role to facilitate secretion clearance in the intubated and ventilated patient and in the patients with chronic respiratory disease such as cystic fibrosis. ${ }^{5-7}$

High-frequency chest wall compressions (HFCWC) is a novel mechanical method applied by a vibratory vest, which induces rapid air movement in and out of the lungs to induce mucolysis and mucus clearance. ${ }^{8} \mathrm{HFCWC}$ has been advocated as a means to standardize the delivery of chest physiotherapy and eliminate of the need for therapist administered treatments. ${ }^{9}$ Clinkscale et $\mathrm{al}^{9}$ also state that, as "conventional chest physical therapy has been associated with various complications, including hypoxemia, arrhythmias, and increased intracranial hypertension, as well as carpal tunnel syndrome for the therapists or nurses providing the treatments, ${ }^{2-4}$ this is further justification for a randomized controlled trial comparison with HFCWC. However, Gobba et al, ${ }^{10}$ in a review of the occupational health evidence, conclude that the "available data are insufficient for an adequate evaluation of the occupational risk related to repetitive movements in health workers," unlike the suggestion from Clinkscale et al. ${ }^{9}$

Clinkscale et $\mathrm{al}^{9}$ undertook a single-center randomized controlled trial of respiratory therapist delivered CCPT (up to 4 times per day after bronchodilator therapy, including manual chest wall percussion and vibration in postural drainage positions, combined with deep breathing and coughing for a total session time of 15-20 min) versus HFCWC (up to 4 times per day after bronchodilator therapy, in the upright position for 15-30 min, with HFCWC applied for more than $15 \mathrm{~min}$ at frequency of $10-15 \mathrm{~Hz}$, interspersed with huffing and coughing as required). There are insufficient details of the CCPT and HFCWC therapy provided to the intubated and mechanically ventilated patient. CCPT/HFCWC was discontinued at the discretion of the respiratory therapist, based on local guidelines for both atelectasis and cystic fibrosis/bronchiectasis. Detail is lacking on the numbers of patients ventilated, ventilation modes used during interventions, and the monitoring of patientventilator synchrony (especially during the delivery of HFCWC).

See the Original Study on Page 221

Primary outcome was hospital stay. Secondary outcomes included intensive care unit stay, duration of mechanical ventilation, time to resolution of lobar atelectasis, occurrence of nosocomial pneumonia, and hospital mortality. Zero rates of nosocomial pneumonia (based on standard clinical criteria) when lobar atelectasis was present in around $70 \%$ of patients in both groups is most surprising and was not discussed by the authors. Physiological changes during or after CCPT and HFCWC were not reported. HFCWC could potentially interfere with the delivery of mechanical ventilation, for example through the triggering of additional ventilator breaths (changes in inspiratory flow "mimic" patient-triggered efforts). Unfortunately, the trial was underpowered for the primary outcome of interest. ${ }^{9}$ The only statistically significant difference (mean difference of 0.3 between groups) was in comfort scores. However, as the same number of patients ( 8 patients each group) experienced intolerable pain/discomfort with both therapies (CCPT and HFCWC), this may indicate the tolerance of both therapies was the same. 
The applicability of the results of randomized controlled trials to individual patients is problematic. Optimal airway clearance may entail the individualized selection of the most appropriate therapy with timely intervention, dependent upon factors such as disease type and severity, patient tolerance, and patient preference. ${ }^{11} \mathrm{HFCWC}$ for secretion clearance during an exacerbation of cystic fibrosis may predispose the patient to substantial arterial desaturation, ${ }^{11}$ presumably to the airway collapse associated with reductions in end-expiratory lung volumes. ${ }^{8}$ In approximately $70 \%$ of patients in the trial ${ }^{9}$ the indications for chest physical therapy included acute lobar atelectasis. It is unclear why HFCWC would be prescribed for the management of acute lobar atelectasis, unless it was due to secretion retention, considering the reductions in end-expiratory lung volume. Positive expiratory pressure and CCPT may be better tolerated (stable oxygenation) during exacerbations of cystic fibrosis, ${ }^{11}$ and the combination of positive expiratory pressure with HFCWC may improve tolerance and efficacy of therapy. ${ }^{8}$ There may also be potential risks with the use of HFCWC to augment secretion clearance in specific disease groups. Central airway occlusion and respiratory distress may occur in patients with poor cough or very tenacious secretions (eg, bronchial casts, severe neuromuscular diseases), unless HFCWC is combined with noninvasive ventilation, ${ }^{12,13}$ nasopharyngeal airway suctioning, mechanical in-exsufflation, ${ }^{14}$ or some form of airway control (endotracheal intubation/tracheostomy to facilitate airway suctioning).

The primary indication for HFCWC is secretion clearance; however, in the short-term, HFCWC may be less effective than conventional chest physical therapy in terms of the weight of secretions cleared. ${ }^{15}$ This may explain why the use of HFCWC may be associated with a greater longitudinal decline in forced expiratory flow during the middle half of the forced vital capacity maneuver $\left(\mathrm{FEF}_{25-75 \%}\right)$ in patients with cystic fibrosis. ${ }^{16}$ Therefore, before HFCWC can be recommended as a sole intervention in cystic fibrosis, more research is needed on both short-term and long-term outcomes.

Cost-effectiveness was not addressed by Clinkscale et al, ${ }^{9}$ and must be investigated, as the additional cost of HFCWC, when there is currently at best potential equivalence with conventional chest physical therapy, may mean the device is not justifiable.

Unfortunately, the trial by Clinkscale et al ${ }^{9}$ fails to provide us with any additional evidence on the optimal secretion clearance therapy in hospitalized patients (nonintubated and intubated). It may be because only $30 \%$ of patients had potentially appropriate indications for intervention (cystic fibrosis, bronchiectasis, or secretion mobilization) and that HFCWC was being used in patients with inappropriate indications (eg, acute lobar atelectasis - trend to reduced time required for resolution in CCPT group). Individualized therapy may improve treatment efficacy and promote patient adherence. For example, the young cystic fibrosis patient may adhere more to HFCWC or Flutter, whereas in the later stages with the near terminal patient, therapist administered CCPT may be more appropriate. ${ }^{16}$

Most importantly, we have yet to determine a gold standard for secretion retention in both the non-intubated and intubated and ventilated patient. A valid and reliable diagnosis of secretion retention will make it feasible to then identify optimal secretion clearance strategies.

\section{George Ntoumenopoulos PhD Grad Dip Clin Epid \\ Physiotherapy Department \\ St Thomas' Hospital \\ London, United Kingdom}

\section{REFERENCES}

1. Gosselink R, Bott J, Johnson M, Dean E, Nava S, Norrenberg M, et al. Physiotherapy for adult patients with critical illness: recommendations of the European Respiratory Society and European Society of Intensive Care Medicine Task Force on Physiotherapy for Critically Ill Patients. Intensive Care Med 2008;34(7):1188-1199.

2. Hodgin KE, Nordon-Craft A, McFann KK, Mealer ML, Moss M. Physical therapy utilization in intensive care units: results from a national survey. Crit Care Med 2009;37(2):561-566.

3. Norrenberg M, Vincent JL. A profile of European intensive care unit physiotherapists. European Society of Intensive Care Medicine. Intensive Care Med 2000;26(7):988-994.

4. Denehy L, Berney S. Physiotherapy in the intensive care unit. Physical Therapy Reviews 2006;11:49-56.

5. Bradley JM, Moran FM, Elborn JS. Evidence for physical therapies (airway clearance and physical training) in cystic fibrosis: an overview of five Cochrane systematic reviews. Respir Med 2006;100(2):191-201.

6. Hess DR. The evidence for secretion clearance techniques. Respir Care 2001;46(11):1276-1293.

7. Jelic S, Cunningham J, Factor P. Clinical review: airway hygiene in the intensive care unit. Crit Care 2008;12(2):209. DOI: 10.1186/cc6830.

8. Dosman C, Jones R. High-frequency chest compression: a summary of the literature. Can Respir J 2005;12(1):37-41.

9. Clinkscale D, Spihlman K, Watts P, Rosenbluth D, Kollef MH. A randomized trial of conventional chest physical therapy versus high frequency chest wall compressions in intubated and non-intubated adults. Respir Care 2011;57(2):221-228.

10. Gobba F, Bacis M, Capodaglio E, De Michieli P, Larese F, Occhionero V. [Risks of repetitive movements in health personnel]. G Ital Med Lav Ergon 2010;32(3):223-226. Article in Italian.

11. Darbee J, Kanga J, Ohtake P. Physiologic evidence for high-frequency chest wall oscillation and positive expiratory pressure breathing in hospitalized subjects with cystic fibrosis. Phys Ther 2005; 85(12):1278-1289.

12. Koga T, Kawazu T, Iwashita K, Yahata R. Pulmonary hyperinflation and respiratory distress following solvent aspiration in a patient with asthma: expectoration of bronchial casts and clinical improvement with high-frequency chest wall oscillation. Respir Care 2004;49(11): 1335-1338. 


\section{High-Frequency Chest Wall Compressions}

13. Yuan N, Kane P, Shelton K, Matel J, Becker B, Moss R. Safety, tolerability, and efficacy of high-frequency chest wall oscillation in paediatric patients with cerebral palsy and neuromuscular diseases:

The author has disclosed no conflicts of interest.

Correspondence: George Ntoumenopoulos PhD Grad Dip Clin Epid, Physiotherapy Department, St Thomas' Hospital, Lambeth Palace Road, London SE1 7EH United Kingdom. E-mail: georgentou@yahoo.com.

DOI: $10.4187 /$ respcare. 01725 an exploratory randomised controlled trial. J Child Neurol 2010; 25(7):815-821. DOI: 10.1177/0883073809350223.

14. Willis D, Warren R. Acute hypoxaemia in a child with neurologic impairment associated with high-frequency chest-wall compression. Respir Care 2007;52(8):1027-1029.

15. Osman LP, Roughton M, Hodson ME, Pryor JA. Short-term comparative study of high frequency chest wall oscillation and European airway clearance techniques in patients with cystic fibrosis. Thorax 2010;65(3):196-200.

16. Sontag M, Quittner A, Modi A, Koenig JM, Giles D, Oermann CM, et al. Lessons learned from a randomised trial of airway secretion clearance techniques in cystic fibrosis. Pediatr Pulmonol 2010;45(3): 291-300. 